\title{
STUDY ON MENTAL HEALTH PROBLEMS AND COUNTERMEASURES OF COLLEGE STUDENTS UNDER THE BACKGROUND OF EPIDEMIC PREVENTION AND CONTROL
}

\author{
Bohong Chao \& Jianwu Fan \\ School of Marxism, Xi'an University of Science and Technology, Xi'an, China \\ received: 21.5.2021; \\ revised: 14.8.2021; \\ accepted: 17.9.2021
}

\section{SUMMARY}

Background: To explore the mental health problems and countermeasures of college students under the background of epidemic prevention and control.

Subjects and methods: A total of 286 students in school were investigated with self-designed social demographic questionnaire, epidemic cognitive behavior, epidemic panic and anxiety questionnaire, depression symptom group scale, heart-filling scale and emotion regulation self-efficacy scale.

Results: College students have a certain understanding of COVID-19 transmission routes, preventive measures, etc., and can actively cooperate and understand the country's epidemic prevention measures. The average score of the College Student Anxiety Self-Rating Scale is (55.37 \pm 6.13$)$ points. The total score of students' emotional regulation self-efficacy is $64.32 \pm 10.61$, the total score

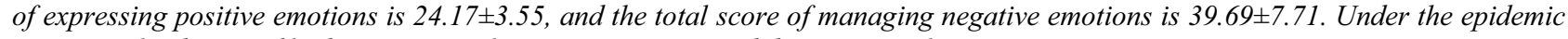
situation, the degree of bad emotions such as panic, anxiety and depression is lower.

Conclusions: The mental health status of college students is on the decline. According to the demographic characteristics and anxiety sources of different students, more social support and targeted and personalized intervention measures should be given to promote their positive mental state.

Key words: epidemic prevention and control - college students - mental health - counter-measure

\section{INTRODUCTION}

A sudden outbreak of COVID-19 made students' study and life completely deviate from the original track. In the face of sudden epidemic, people's psychology has experienced various fluctuations. The mental health status of college students in the context of epidemic prevention and control is different from other time periods, and college students are in the stage of rapid development in physiology, psychology and social cognition, which is more prone to psychological crisis than other age groups, which reminds us to pay special attention to the mental health status of college students in the context of epidemic prevention and control (Chen et al. 2019, Abuhmain \& Al-Majali 2020, Karasar \& Canli 2020).

During the period of COVID-19 epidemic, how to improve the mental health level of college students, treat the epidemic correctly, and overcome the epidemic with a positive attitude and emotion will be the most urgent work for colleges and universities during the period of epidemic prevention and control (Goodsett et al. 2020). In this paper, by randomly distributing questionnaires among the students in school, using the stress theory in psychology, and statistically analyzing the questionnaires, we can fully understand the current psychological state of college students and put forward corresponding countermeasures, so as to promote the healthy growth of college students.
As an important supporting force for the development of the country and society, college students are regional, widely distributed, highly active and self-conscious, and easy to accept new things. When faced with the COVID-19 epidemic, they will also have negative emotions. Therefore, studying and analyzing the mental health of freshmen is of great significance to the country, schools, parents and individuals.

The state has issued a series of mental health and mental health-related policy documents, which have strengthened the treatment of mental disorders during the new coronavirus epidemic. Therefore, it is imperative to carry out mental health investigation on college students, which is also an important way to effectively implement party's policies and guidelines. It is conducive to the allround development of the comprehensive quality of the social successors of the motherland and is more conducive to the long-term prosperity of the country.

Through the data and information, the school management department can fully grasp the students' trends, and then understand their ideological changes, and carry out causal analysis on students' thoughts and behaviors, so as to promote the ideological and political work in colleges and universities in China to keep pace with the times and change according to events. If students are found to have serious psychological problems, they can inform parents in time, let students seek medical treatment as soon as possible, find solutions, ensure students' safety and serve students better. 
Many parents don't pay attention to psychological problems, and even don't know what psychological problems are. We can popularize psychological knowledge to parents from the school level, help parents realize that students with psychological problems can't be ignored, let alone blamed, and better cooperate with schools to do a good job in students' psychological problems.

\section{SUBJECTS AND METHODS}

A full-coverage survey was conducted among college students in university. A total of 300 questionnaires were distributed and 286 valid questionnaires were recovered, with a questionnaire recovery rate of $95.3 \%$. Among them, 106 boys accounted for $37.1 \%$, and 180 girls accounted for $62.9 \%$. Taking Questionnaires website as the content-bearing tool, the questionnaire was distributed to all the students staying in the university to fill in. After the questionnaire was collected, 85 students were interviewed by telephone one to one according to the feedback results.

Set 10 basic questions, including: gender, grade, epidemic situation in the area, whether living expenses can meet the demand, family population, short-term plan, nature of parents' or family members' work, frequency of going out in a week, physical health and emotional situation.

On the basis of Kessler's Six Mental Disorders Scale and its related research, the mental health assessment problem was designed and revised (Linardon et al. 2019). Pre-investigation shows that the content is effective. Finally, a total of 10 mental health assessment questions were set up. The degree is measured by a five-level scale, and the mental health symptoms included in the scale are as follows: "Can't live normally", "fidgety", "decadent", "worried about family", "still nervous about epidemic situation", "worried about the future", "lonely", "communication barrier", "emotional fluctuation, cynicism", "inattention, difficult decision-making and poor self-control".

The value of Cronbach alpha after overall standardization is equal to 0.72 , which has good reliability. KMO statistic is 0.87 , which is greater than 0.5 . The questionnaire has good structural validity. The significance of Bartlett sphericity test is 0.00 , less than 0.01 , and the data is in good condition.

Based on the nine criteria of depression in Diagnostic and Statistical Manual of Mental Diseases published by American Psychiatric Association, it is very sensitive to the changes of depressive symptoms (Gu et al. 2019). According to the scoring criteria, the scores of depression symptom group scale were divided into five groups: 9-13, 14-18, 19-23, 24-28, 29-36, corresponding to no, mild, moderate, moderate and severe depression respectively. In this study, Cronbach alpha coefficient of this scale is 0.893 .

\section{Statistical analysis}

SPSS 21.0 software was used for statistical analysis. The measurement data conforming to normal distribution is expressed by $(\overline{\mathrm{x}} \pm \mathrm{s})$, and the comparison of independent sample means is tested by t. Counting data is expressed by $\mathrm{n}(\%)$, and the comparison of independent sample rates is tested by $\chi^{2}$; Logistics regression model was used to analyze the influencing factors. $\mathrm{P}<0.05$ means the difference is statistically significant.

\section{RESULTS}

According to the survey, all the respondents $(100 \%)$ are concerned about the epidemic, but there are differences in the degree of attention. $85.13 \%$ students are very concerned about the epidemic, and only $5.22 \%$ students pay little attention to the epidemic. $38.21 \%$ were within 1 hour, $42.82 \%$ were within $1-2$ hours, $12.53 \%$ were within $2-3$ hours and $6.59 \%$ were over 3 hours.

In this survey, the average score of college students' self-rating anxiety scale is $(55.37 \pm 6.13)$. Among them, $55.28 \%$ of college students have no anxiety, $43.09 \%$ have anxiety, including $57.01 \%$ mild anxiety, $33.93 \%$ moderate anxiety and $10.28 \%$ severe anxiety. For details, see Figure 1. Scores of the overall level of mental health of college students (see Table 1).

Table 1. Scores on the overall level of mental health of college students $(\mathrm{n}=286)$

\begin{tabular}{lcc}
\hline Level & Score & Total number of people \\
\hline Serious & $10-20$ & 25 \\
Moderate & $20-30$ & 127 \\
Mild & $30-40$ & 96 \\
Health & $40-50$ & 38 \\
\hline
\end{tabular}

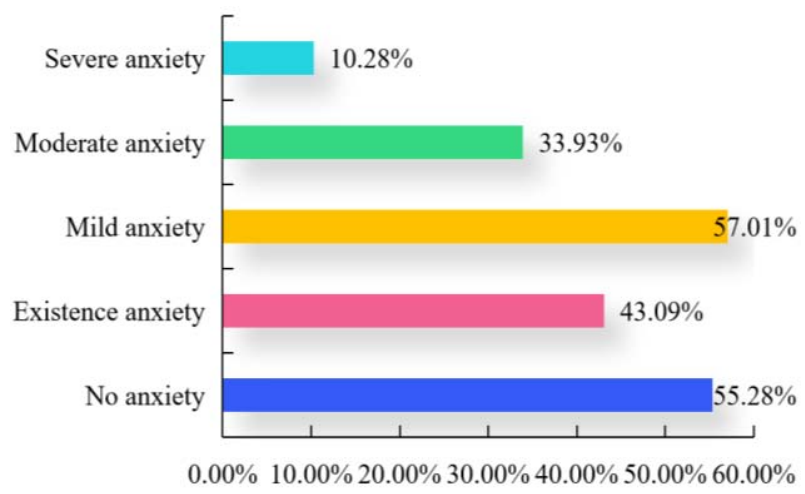

Figure 1. Mental health of college students

Emotional self-efficacy refers to an individual's confidence in managing his emotional state effectively, which can ease emotional tension, maintain emotional regulation, help regulate emotional impulse and promote mental health. 
Table 2. Correlation analysis of mental health indicators

\begin{tabular}{|c|c|c|c|c|c|}
\hline Project & Epidemic panic & $\begin{array}{l}\text { Epidemic } \\
\text { anxiety }\end{array}$ & $\begin{array}{l}\text { Depressive } \\
\text { symptoms }\end{array}$ & Hearty level & $\begin{array}{l}\text { Adjust emotional } \\
\text { self-efficacy }\end{array}$ \\
\hline Epidemic panic & 1.000 & & & & \\
\hline Epidemic anxiety & $0.451^{* *}$ & 1.000 & & & \\
\hline Depressive symptoms & $0.336^{* *}$ & $0.382 * *$ & 1.000 & & \\
\hline Hearty level & $-0.092 * *$ & $-0.085 * *$ & $-0.328 * *$ & 1.000 & \\
\hline Adjust emotional self-efficacy & $-0.096 * *$ & $-0.071 * *$ & $-0.346^{* *}$ & $0.682^{* *}$ & 1.000 \\
\hline
\end{tabular}

Note: ${ }^{*} \mathrm{P}<0.05 ; * \mathrm{P}<0.01$

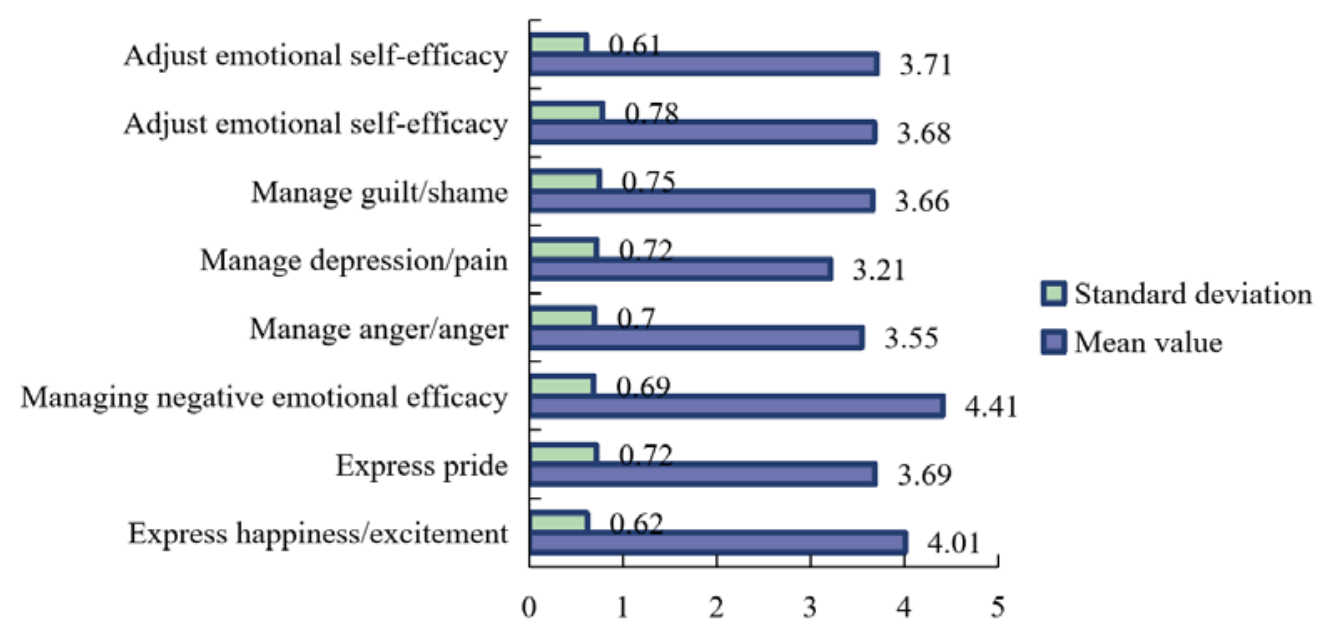

Figure 2. Adjust the score of emotional self-efficacy

The survey results showed that the total score of students' emotional regulation self-efficacy was $64.32 \pm 10.61$, the total score of expressing positive emotions was $24.17 \pm 3.55$, and the total score of managing negative emotions was $39.69 \pm 7.71$. Taking the next standard deviation of the average as the scoring standard, those higher than one standard deviation are the high segments, those lower than one standard deviation are the low segments, $13.24 \%$ of the students are in the high segments and $17.63 \%$ are in the low segments. The dimensional mean of expressing positive emotional efficacy is higher, but the dimensional mean of managing negative emotional efficacy is lower, and the emotional efficacy of managing anger/anger is the lowest. See figure 2 for specific data.

By using Spearman correlation coefficient to evaluate the correlation degree of each mental health index, we found that all mental health indexes of students under COVID-19 epidemic were highly correlated, and students with high level of personal happiness and strong self-efficacy of emotion regulation felt the lower degree of bad emotions such as panic, anxiety and depression. See table 2 for specific data.

\section{DISCUSSION}

The analysis shows that college students generally pay more attention to COVID-19 epidemic, and take time out every day to understand the epidemic prevention and control situation, and at the same time have a certain understanding of the transmission route, spread reasons and preventive measures of COVID-19 epidemic. A small number of respondents indicated that they had limited information at school, which was largely related to the fact that the school was on vacation (Wei et al. 2020).

The results showed that the proportion of students' anxiety in epidemic areas was significantly higher than that in non-epidemic areas $(\mathrm{P}<0.05)$. Colleges and universities should know the psychological needs of these students in time, do a good job of appeasement for students, and ensure that they finish the online teaching schedule on schedule, so as to reduce the psychological gap caused by the difference between them and the students' learning schedule. At the same time, the study confirmed that the anxiety degree of medical students was obviously lower than that of nonmedical students. Perhaps medical students, out of professional instinct, pay more attention to the understanding of epidemic dynamics, can objectively and rationally look at the situation of epidemic prevention and control in China, and know how to deal with it, so they are accompanied by a more active mental health state (Dong et al. 2020).

The results show that the physical health of college students will affect their mental health. Most students feel that their physical fitness declines during the epidemic, and they are prone to fatigue, and even some students are nervous and unable to relax. Bad emotions 
are bad for health, such as long-term depression of sadness and crying, which can easily cause respiratory diseases. This is consistent with the research conclusion in the literature (Geng et al. 2019), which puts the subjects in an objective isolation environment, causing real subjective emotional loneliness. The results show that loneliness and hunger are dominated by the same kind of signals in the same brain area, and people's needs for social connections are as important as their dietary needs (Rakhmanov et al. 2020). Lonely emotional experience can lead to negative reactions of the body. Similarly, mental health problems such as nervousness and irritability can induce various health problems.

Through analysis, we can find that with the development of the epidemic, we can find that the degree of panic and anxiety of college students about the epidemic is on the rise. At the same time, we think that the epidemic has a greater impact on the normal life of families, and there is a certain degree of negative and pessimistic attitude towards the prevention and control of the epidemic. Facing the pressure brought by the normalized epidemic prevention and control, the society should pay more attention to the mental health of college students, combine the needs of college students' training and mental health guidance, and increase the social support for college students, so as to help college students reduce the pressure and negative emotions brought by the normalized epidemic prevention and control (Shi et al. 2020).

On the one hand, the government should shoulder its own responsibilities, combine the training needs of college students, aim at the situation of normal epidemic prevention and control, reduce the employment pressure of college students through government guidance, comprehensively improve the enrollment and employment programs, and provide more choices for college students, thus reducing the employment pressure of college students and ensuring their mental health.

On the other hand, families should give full play to their caring role, constantly combine the growing needs of college students, care about the psychological problems of college students, and help college students solve their negative emotions through family care, so as to create a good family environment for college students, thus reducing their psychological pressure and promoting their mental health development.

During the epidemic period, college students should learn to distinguish various kinds of comments on the Internet, hold the most basic distinguishing ability, prevent false comments from affecting their mood, and choose official and authoritative channels to obtain all kinds of information. When you find that you have abnormal emotions compared with yourself some time ago, your peers and normal people in society, you should talk in time and seek help from others. The official network platform of the school should update the latest epidemic news in time, construct a column related to mental health education and support for epidemic prevention, carry out mental health education and popular science propaganda for students, and make a solid network backing.

COVID-19 epidemic has brought certain pressure and psychological burden to everyone. In the stress theory, because everyone has different ability to resist pressure, their performance in the face of such unexpected events will be quite different. If excessive attention to epidemic situation brings great psychological pressure, it will not only affect normal life, but also affect one's own immunity (Zhong et al. 2020).

First of all, at present, some universities and related organizations have provided mental health services of "cloud consultation", providing psychological assistance to students in need one by one, and achieved certain results. Through online sharing, daily psychological life skills, telephone communication and other heartto-heart conversation activities, we can repair the anxiety and panic among college students, set up channels for students to talk and resolve, correctly face the COVID-19 epidemic, maintain a calm and calm mind, and achieve "no panic, no fear, no anxiety" to improve their psychological adaptability.

Secondly, it is necessary to guide all kinds of students correctly. In the face of emergencies, a series of physical and psychological changes will occur. At the same time, to make a reasonable study plan, graduates should arrange their time reasonably, correctly understand the impact of the epidemic, and take practical actions to deal with employment, graduation and other issues.

In addition, students who need to be isolated for various reasons should be reminded to cooperate with relevant management, take care of their lives as much as possible, communicate more, communicate more, listen more, and keep a good mental state, and be told that they can enhance their psychological reaction function during the epidemic by diverting attention and changing cognition.

\section{CONCLUSIONS}

Under the COVID-19 epidemic, college students present the following mental health characteristics: cognition and behavior can be kept rational, and mental health status shows a downward trend, which is characterized by large emotional fluctuations and obvious negative emotions, and positive psychosocial functions and self-efficacy are damaged to a certain extent. Therefore, in the mental health education in the future, various measures should be taken to improve the psychological ability of coping with stress state according to the characteristics of college students' cognition, emotion and behavior, so as to ensure that college students can quickly recover from the psychological impact of the epidemic. 


\section{Acknowledgements: None.}

Conflict of interest: None to declare.

\section{Contribution of individual authors:}

All authors contribute equally in this study.

\section{References}

1. Abuhmaidan Y, Al-Majali S: The Impact of the Coronavirus Pandemic on Mental Health among Al Ain University Students in Light of some Demographic Variables. Psychiatr Danub 2020; 32:482-490

2. Chen X: Research on College Students"'" Online Learning Process Control under the Background of Big Data. Management Science and Research: Chinese and English Version 2019; 8: 49-51

3. Dong $H$, Yang $F$, Lu $X$, et al: Internet addiction and related psychological factors among children and adolescents in China during the coronavirus disease 2019 (COVID19) epidemic. Frontiers in Psychiatry 2020; 11: 751

4. Geng H, Guang-yu L: The Connotation and Strategy of College Students' Behavior Analysis under the Background of Big Data, Proceedings of the 2019 International Conference on Big Data and Education 2019: 48-51

5. Goodsett M: Best practices for teaching and assessing critical thinking in information literacy online learning objects. The Journal of Academic Librarianship 2020; 46: 102163

6. Gu ZY, Li YH: A Study on the Influence Factors of College Students' Mobile Search Behavior under the Background of "Internet +". Journal of tangshan normal university 2019; 041: 119-124

7. Karaşar B, Canli D: Psychological Resilience and Depression during the Covid-19 Pandemic in Turkey. Psychiatr Danub 2020; 32:273-279

8. Linardon J, Shatte A, Messer M, et al.: E-mental health interventions for the treatment and prevention of eating disorders: An updated systematic review and metaanalysis. Journal of consulting and clinical psychology 2020; 88: 994

9. Rakhmanov O, Dane S: Knowledge and Anxiety Levels of African University Students Against COVID-19 During the Pandemic Outbreak by an Online Survey. Journal of Research in Medical and Dental Science 2020; 8: 53-56

10. Shi KY: Analysis of Mental Health Status of Medical Students in the Late Stage of COVID-19 Epidemic. Advances in Psychology 2020; 10: 1357-1362

11. Wei, M, Liu: The Application Status of Horticultural Therapy in the Study of College Students' Physical and Mental Health. Journal of Landscape Research 2020; 12: 108-110

12. Zhong BL, Zhou DY, He MF, et al: Mental health problems, needs, and service use among people living within and outside Wuhan during the COVID-19 epidemic in China. Annals of Translational Medicine 2020; 8: 1392-1392

Correspondence:

Bohong Chao

School of Marxism, Xi' an University of Science and Technology

$X i^{\prime}$ an, 710054, China

Email:bohongbhcbhc@xxxhi.cc 